\title{
Correction to: Responsible AI and Analytics for an Ethical and Inclusive Digitized Society
}

\author{
Denis Dennehy (D), Anastasia Griva (D), Nancy Pouloudi (D), \\ Yogesh K. Dwivedi (D), Ilias Pappas (D), and Matti Mäntymäki (D)
}

\section{Correction to: \\ D. Dennehy et al. (Eds.): Responsible AI and Analytics for an Ethical and Inclusive Digitized Society, LNCS 12896, https://doi.org/10.1007/978-3-030-85447-8}

For Chapter 29:

In an older version of this paper, only one of Devinder Thapa's two affiliations was listed. This has been corrected.

For Chapter 34:

In an older version of this paper, the term "adaptive agility" was employed instead of "entrepreneurial agility" in one of the last sentences in Sect. 5.2. This has been corrected.

The updated version of these chapters can be found at https://doi.org/10.1007/978-3-030-85447-8_29

https://doi.org/10.1007/978-3-030-85447-8_34

(C) IFIP International Federation for Information Processing 2021

Published by Springer Nature Switzerland AG 2021

D. Dennehy et al. (Eds.): I3E 2021, LNCS 12896, p. C1, 2021.

https://doi.org/10.1007/978-3-030-85447-8_66 